\title{
Non-invasive detection for work stress among the professional medical nurses during COVID-19 in Mongolia
}

Munkhkhand Jurmeddorj ${ }^{1}$, Otgonbaatar Dondonkhuu ${ }^{2}$, Naranbaatar Nyam ${ }^{1}$, Ariunaa Damdinsuren ${ }^{3}$ and Aldarmaa Tundevrentsen ${ }^{4, *}$

${ }^{1}$ Nursing School, Mongolian National University of Medical Sciences, Mongolia

${ }^{2}$ Civil Servant Central Hospital, Mongolia

${ }^{3}$ School of Pharmacy, Mongolian National University of Medical Sciences, Mongolia

${ }^{4}$ Biomedical School, Mongolian National University of Medical Sciences, Mongolia

* Correspondence: aldarmaa2007@gmail.com; Tel.: +976-88989839

Received: 30 June 2021; Accepted: 22 October 2021; Published: 26 November 2021

Edited by: Norshariza Nordin (Universiti Putra Malaysia, Malaysia)

Reviewed by: Tahamina Begum (Universiti Sains Malaysia, Malaysia);

Hasni Idayu Saidi (Universiti Putra Malaysia, Malaysia)

https://doi.org/10.31117/neuroscirn.v4i3Suppl.87

\begin{abstract}
COVID-19 pandemic has created a lot of work stress, especially among medical professionals, namely among nurses. The absence of the non-invasive stress detecting method using salivary alpha-amylase test in Mongolia served us to perform this study. We consider that the nurse immunization could be managed and boosted if the work stress is detected, and it would serve as the prevention method from the infections in the clinical settings. The study aims to investigate the stress level among medical professionals, particularly the nurses, using a self-report questionnaire, work stress profile, and salivary alpha-amylase during the initial period of the COVID pandemic. In the mid of March 2020, 356 professional medical nurses from three national tertiary centres of Mongolia were involved in this study. We employed a Work Stress Profile (WSP), a selfadministered questionnaire that assists the personnel to identify their perceived stressors and assessing the stress at work. As the physical stress marker, we measured the saliva alpha-amylase level in these participants. The vital signs, heart rate, glucose and blood pressure were measured. The correlation method was used. There were 344 females and 12 males. The participants' mean age was $38 \pm 9.6$ years old. The stress among the medical professionals was high by WSP - it was counted 342 or $96.1 \%$ of the personnel suffering from the stress at work: the WSP average was $151.49 \pm 26.81$. However, age, education and work experience could influence stress at a certain level. The salivary alpha-amylase and WSP scores were correlated directly $(p<0.01$; $r=0.187)$. The pulse, diastolic blood pressure and salivary alpha-amylase were interrelated. As one of the important personnel at the hospital, nurses are at high risk to get stressed in Mongolia. We concluded that the overloading of work leads to work stress among professional medical nurses, especially during the COVID19 pandemic.
\end{abstract}

Keywords: nurse; salivary alpha amylase; work; stress;

C2021 by Jurmeddorj et al. for use and distribution according to the Creative Commons Attribution (CC BY-NC 4.0) license (https://creativecommons.org/licenses/by-nc/4.0/), which permits unrestricted non-commercial use, distribution, and reproduction in any medium, provided the original author and source are credited.

\subsection{INTRODUCTION}

The COVID-19 has been spreading rapidly across the globe, particularly, the health sector is at a high risk of infections. Consequently, the personnel who deliver direct medical care to the clients could experience stress at their work. As it was noted by Rice (1999), American researchers define stress at work as "work requirements that go beyond the worker's handling capability", and half of one's waking hours are spent at work; therefore, negative stressors not only affect a 
person's work and health but considerably disturbs the hospitals. The high workplace demands, overresponsibility, and over-authority have been identified as serious sources of occupational stress among nursing staff (Otgonbaatar et al., 2020). The expression "stress" is becoming a more common usage for the modern world population. Notably, during this pandemic period, the stress is striking the clinical personnel, especially nurses. Looking for a non-invasive way to detect whether Mongolian medical professionals are in the front line thus the stress regarding the works is existing; we found out that there has not been any study on revealing the stress by the salivary alpha-amylase in this country.

In Mongolia, there were registered 11,169 physicians and 12,344 nurses who work in health organizations, and in 2018 it was estimated that 38.6 nurses per 10,000 population mean the ratio is lower than the global average standard. This could be served as the main factor for the medical professional's work stress.

The medical profession is stressful; accordingly, the personnel are vulnerable to the effects of stress in their daily environment, manifested through emotional exhaustion, followed by an emotional numbness or a negative attitude towards oneself and others (Maslach et al., 2001). Physicians, nurses, and other medical personnel have complex and demanding jobs. A combination of high workplace requirements, overresponsibility, and over-authority has been identified as a major source of job or work stress among medical staff (Lusk, et al., 2007). It is impossible to eliminate workrelated stress and stressors, but only effective coping techniques can help (Benson et al., 1974). Medical workers who have the closest contact with a client need to examine stressful situations in their work. At the physiological level, this includes both central and peripheral nervous system activation and coordination. These systems interact with the immune system and thus play an important role in the pathogenesis of stress-related diseases (Sternberg, 2006). Salivary alpha-amylase has emerged as a valid and reliable stress marker over the last 15 years. It can be measured quickly and noninvasively through saliva collection (Ali \& Nater, 2020).

Information about COVID-19 cases came in January 2020, and two months later, the first imported case in Mongolia was detected in March. Ten months later, we had a local outbreak. This event had a striking impact on Mongolian medical professionals. Consequently, this occasion served as the background of detecting and evaluating the medical professionals' stress levels. In this study, we focused on evaluating the stress among nurses by measuring the level of salivary alpha-amylase in the participants as well as the physical stress marker and other vital signs such as blood pressure, glucose, and heart rate.

\subsection{MATERIALS AND METHODS}

\subsection{Study design -Data source and study population}

The nurse work stress evaluation study was performed using the cross-sectional method of the analytical study design. There were registered 518 medical professionals at the three main national centres of Mongolia. We involved 356 nurses as medical professionals. 344 female and 12 male medical professionals got the informed consent and fulfilled the inclusion criteria. We excluded the participants who had taken steroid pills for the last two weeks, did not have alcoholic drinks in 24 hours and worked in two places. The participants mean age was $38 \pm 9.6$ years old. The stress among the medical professionals was high by WSP - it was counted 342 , or $96.1 \%$ of the personnel suffering from the stress at work. However, age, education and work experience could be triggering the stress. The questionnaire was obtained with the informed consent of all participants. The institutional review board of the MNUMS approved the methods, code 2020/3-02.

\subsection{Variable and measurements}

Work Stress Profile questionnaire: We employed a Work Stress Profile (WSP) questionnaire of Rice in 57 questions in 3 domains; the questions aimed to assess the coworker's relationship (1-26), the working environment (27-48), and the personal attribute (4957). This questionnaire was designed in a manner to reveal how nurses perceive and accept the stress. The WSP' collective totals' score: low stress $(<91-111)$, normal stress (112-140), and high stress (>141-167).

Salivary alpha-amylase measurement: For the physical stress marker, we measured the level of alpha-amylase in the saliva of the nurses using the saliva amylase monitor-2004. The fabricated salivary amylase activity monitor consists of three devices, the salivary transcription device, a testing strip and an optical analyzer. Firstly, in the morning, each participant put the test strip under the tongue for 30 seconds, and the reading was recorded.

Stress and vital signs: Blood glucose, pressure, and pulse were also measured with the appropriate apparatus in 
the morning and evening. Criteria were determined using a cross-sectional model of the study.

\subsection{Statistical analysis}

The given data was analyzed by SPSS (Statistical Packages for Social Science) 25.0 software. The standard deviation (SD) was used to express means of the study characteristics for normally variables and numbers with percentages in cases of categorical data. The frequency distributions of categorical variables were analyzed using the Pearson Chi-Square test and linear general analysis. We employed Student's T-test for continuous variables presenting the differences between the groups. The linear correlations of the WSP collective total score and salivary alpha-amylase levels with some vital sign variables were analyzed. In univariate regression analysis, associations of study characteristics with salivary alpha-amylase levels were tested respectively. The statistically significant difference is calculated to be $p<0.05$.

\subsection{RESULTS}

The WSP revealed that $96.1 \%$ or 342 of the medical professionals were at high risk of stress at their work.
The work stress evaluation by the questionnaire and salivary alpha-amylase levels was directly correlated.

A total of 356 medical professionals who worked in three referral hospitals participated in this study. Table 1 demonstrates that 344 (96.6\%) were females and 12 (3.4\%) were males. The mean age of the participants was $38 \pm 9.6$ years old -103 (28.9\%) 25-30 years old, 135 (37.9\%) 41-50 years old. 215 (60.4\%) had bachelor's degree diplomas and 181 (50.8\%) had been working for more than 10 years in the hospitals.

Most of the participants, 220 (61.8\%), suffered from high stress. Due to age and stress level interrelationship, four $(22.2 \%)$ participants in the $18-24$ years old age group had no stress. 60 (76.9\%) professionals aged 3140 experienced high stress. It revealed that stress level is influenced by age. Medical professionals with bachelor and master degree has low and high stress levels, respectively. Meanwhile the professionals who has worked more than 10 years felt highly stressed (Table 1).

Table 1: WSP relations to general characteristics

\begin{tabular}{|c|c|c|c|c|c|c|c|c|c|c|c|}
\hline \multirow{3}{*}{ Characteristics } & \multirow{2}{*}{\multicolumn{2}{|c|}{$\begin{array}{l}\text { Total } \\
\mathrm{N}=356\end{array}$}} & \multirow{2}{*}{\multicolumn{2}{|c|}{$\begin{array}{c}\text { None } \\
\mathrm{N}=14 \\
(3.9 \%)\end{array}$}} & \multicolumn{6}{|c|}{ Stress ( $N=342,96.1 \%)$} & \multirow{3}{*}{$P$ value } \\
\hline & & & & & \multicolumn{2}{|c|}{$\begin{array}{c}\text { Low } \\
(\mathrm{N}=17,4.8 \%)\end{array}$} & \multicolumn{2}{|c|}{$\begin{array}{c}\text { Moderate } \\
(\mathrm{N}=105,29.5 \%)\end{array}$} & \multicolumn{2}{|c|}{$\begin{array}{c}\text { High } \\
(\mathrm{N}=220,61.8 \%)\end{array}$} & \\
\hline & $\mathrm{N}$ & $\%$ & $\mathrm{~N}$ & $\%$ & $\mathrm{~N}$ & $\%$ & $\mathrm{~N}$ & $\%$ & $\mathrm{~N}$ & $\%$ & \\
\hline \multicolumn{12}{|c|}{ Gender } \\
\hline Female & 344 & 96.6 & 13 & 3.8 & 16 & 4.7 & 104 & 30.2 & 211 & 61.3 & \multirow{2}{*}{0.365} \\
\hline Male & 12 & 3.4 & 1 & 8.3 & 1 & 8.3 & 1 & 8.3 & 9 & 75.0 & \\
\hline \multicolumn{12}{|c|}{ Age (years) } \\
\hline $18-24$ & 18 & 5.1 & 4 & 22.2 & 3 & 16.7 & 5 & 27.8 & 6 & 33.3 & \multirow{5}{*}{$0.001 *$} \\
\hline $25-30$ & 103 & 28.9 & 5 & 4.9 & 5 & 4.9 & 37 & 35.9 & 56 & 54.4 & \\
\hline $31-40$ & 78 & 21.9 & 1 & 1.3 & 3 & 3.8 & 14 & 17.9 & 60 & 76.9 & \\
\hline $41-50$ & 135 & 37.9 & 3 & 2.2 & 4 & 3.0 & 42 & 31.1 & 86 & 63.7 & \\
\hline Above 50 & 22 & 6.2 & 1 & 4.5 & 2 & 9.1 & 7 & 31.8 & 12 & 54.5 & \\
\hline \multicolumn{12}{|c|}{ Education } \\
\hline Diploma & 129 & 36.2 & 4 & 3.1 & 7 & 5.4 & 34 & 26.4 & 84 & 65.1 & \multirow{3}{*}{0.764} \\
\hline Bachelor & 215 & 60.4 & 10 & 4.7 & 10 & 4.7 & 68 & 31.6 & 127 & 59.1 & \\
\hline Master & 12 & 3.4 & 0 & 0.0 & 0 & 0.0 & 3 & 25.0 & 9 & 75.0 & \\
\hline \multicolumn{12}{|c|}{ Working experience } \\
\hline$<1$ year & 36 & 10.1 & 3 & 8.3 & 2 & 5.6 & 11 & 30.6 & 20 & 55.6 & \multirow{4}{*}{0.761} \\
\hline $1-3$ years & 42 & 11.8 & 3 & 7.1 & 3 & 7.1 & 12 & 28.6 & 24 & 57.1 & \\
\hline $3-10$ years & 97 & 27.2 & 4 & 4.1 & 5 & 5.2 & 29 & 29.9 & 59 & 60.8 & \\
\hline$>10$ years & 181 & 50.8 & 4 & 2.2 & 7 & 3.9 & 53 & 29.3 & 117 & 64.6 & \\
\hline
\end{tabular}

*Pearson Chi-Square Test 
We evaluated the stress level based on the salivary alpha-amylase level - 310 (65.5\%) medical professionals were highly stressed. The Student's T-test was employed to analyze the salivary alpha-amylase average levels, and some cardiovascular characteristics comparing the non-stress and stressed groups: salivary alpha-amylase $(13.29 \pm 6.41$ vs. $28.81 \pm 22.59 \mathrm{kU} / \mathrm{L})$; systolic blood pressure $(122.57 \pm 10.73$ vs. $123.13 \pm 11.96$ $\mathrm{mmHg})$, diastolic blood pressure $(71.71 \pm 7.08$ vs. $77.35 \pm 9.01 \mathrm{mmHg}) ;$ and pulse $(70.93 \pm 6.11$ vs. $78.23 \pm 9.73 \mathrm{bpm})$. We noticed the statistical significance, the participants' salivary alpha-amylase level, diastole and pulse average are higher than the professionals without stress $(p<0.05)$ (Table 2$)$.

The salivary alpha-amylase levels had direct weak correlation with 3 domains of WSP: co-worker's relationship $(r=0.145, p<0.01)$, working environment $(r=0.183, p<0.01)$ and personal attribute $(r=0.116$, $\mathrm{p}<0.05)$. And diastolic blood pressure was correlated directly but weak with the two domains: co-workers' relationship $(r=0.105, p<0.05)$ working environment $(r=0.169, p<0.01)$ (Table 3).

The study results exposed a determination coefficient $\mathrm{R}=0.286$; it means that age, gender, education and work experiences had $28 \%$ influences on the collective totals score. The participants salivary alpha-amylase levels are added by one unit the WSP score is increased by 0.216 with $\mathrm{Cl}$ (0.076-0.357) (Table 4).

Figure 1 demonstrates workplace stress collective totals score was correlated to salivary alpha-amylase and diastole blood pressure. The salivary alpha-amylase and WSP score were weakly correlated $(r=0.187, p<0.01)$. It was noticed that if the collective totals score is high the salivary alpha-amylase levels increased. Moreover, the diastolic blood pressure $(r=0.152, p<0.01)$ is weakly correlated to stress collective totals score. Our finding demonstrates a strong correlation between blood sugar and heart rate during workplace stress (Figure 1).

Table 2: Some physiological characteristics and salivary alpha-amylase level (by stress)

\begin{tabular}{|c|c|c|c|c|}
\hline \multirow{2}{*}{ Variables } & \multirow{2}{*}{ Total } & \multicolumn{2}{|c|}{ Stress } & \multirow{2}{*}{$P$ value } \\
\hline & & No & Yes & \\
\hline Salivary alpha-amylase (kU/L) & $28.20 \pm 22.38$ & $13.29 \pm 6.41$ & $28.81 \pm 22.59$ & $0.01^{*}$ \\
\hline Systolic BP (mmHg) & $123.11 \pm 11.90$ & $122.57 \pm 10.73$ & $123.13 \pm 11.96$ & 0.864 \\
\hline Diastolic BP (mmHg) & $77.12 \pm 9.00$ & $71.71 \pm 7.08$ & $77.35 \pm 9.01$ & $0.02 *$ \\
\hline Pulse (bpm) & $77.94 \pm 9.71$ & $70.93 \pm 6.11$ & $78.23 \pm 9.73$ & $0.01 *$ \\
\hline Glucose (mmol/L) & $6.12 \pm 4.10$ & $5.61 \pm 0.58$ & $6.14 \pm 4.18$ & 0.634 \\
\hline
\end{tabular}

Data are expressed in mean \pm SD.

$* P<0.05$ based on independent samples $t$ test.

Table 3: Correlation of WSP to salivary alpha-amylase and cardiovascular characteristics

\begin{tabular}{lcccc}
\hline Variables & $\begin{array}{c}\text { Coworkers } \\
\text { Relationship }\end{array}$ & $\begin{array}{c}\text { Working } \\
\text { environment }\end{array}$ & $\begin{array}{c}\text { Personal } \\
\text { attribute }\end{array}$ & $\begin{array}{c}\text { Collective } \\
\text { totals score }\end{array}$ \\
\hline SAA & $.145^{* *}$ & $.183^{* *}$ & $.116^{*}$ & $.187^{* *}$ \\
Systolic BP & 0.028 & 0.052 & 0.044 & 0.050 \\
Diastolic BP & $.105^{*}$ & $.169^{* *}$ & 0.074 & $.152^{* *}$ \\
Pulse & 0.099 & $.118^{*}$ & 0.074 & $.123^{*}$ \\
Glucose & -0.006 & 0.030 & 0.061 & 0.029 \\
\hline
\end{tabular}

${ }^{*} P<0.05 ;{ }^{* *} P<0.01$ 
Table 4: Regression of the vital signs on collective total score

\begin{tabular}{|c|c|c|c|c|c|c|c|c|}
\hline & \multirow{2}{*}{ Model } & \multicolumn{2}{|c|}{$\begin{array}{c}\text { Unstandardized } \\
\text { Coefficients }\end{array}$} & \multirow{2}{*}{$\begin{array}{c}\begin{array}{c}\text { Standardized } \\
\text { Coefficients }\end{array} \\
\text { Beta }\end{array}$} & \multirow{2}{*}{$\mathbf{t}$} & \multirow{2}{*}{ Sig. } & \multicolumn{2}{|c|}{$\begin{array}{c}95.0 \% \text { Confidence } \\
\text { Interval for B }\end{array}$} \\
\hline & & B & $\begin{array}{l}\text { Std. } \\
\text { Error }\end{array}$ & & & & $\begin{array}{l}\text { Lower } \\
\text { Bound }\end{array}$ & $\begin{array}{l}\text { Upper } \\
\text { Bound }\end{array}$ \\
\hline \multirow{9}{*}{1} & Age & 3.572 & 2.017 & 0.124 & 1.771 & 0.078 & -0.396 & 7.539 \\
\hline & Gender & 5.212 & 8.771 & 0.031 & 0.594 & 0.553 & -12.039 & 22.464 \\
\hline & Education & -2.148 & 2.944 & -0.038 & -0.729 & 0.466 & -7.938 & 3.643 \\
\hline & Work experience & 1.451 & 2.111 & 0.048 & 0.687 & 0.492 & -2.701 & 5.602 \\
\hline & Salivary Alpha Amylase & 0.216 & 0.071 & 0.160 & 3.031 & 0.003 & 0.076 & 0.357 \\
\hline & Systolic BP & -0.124 & 0.167 & -0.049 & -0.739 & 0.461 & -0.453 & 0.206 \\
\hline & Diastolic BP & 0.419 & 0.233 & 0.125 & 1.802 & 0.072 & -0.038 & 0.876 \\
\hline & Pulse & 0.208 & 0.177 & 0.067 & 1.178 & 0.240 & -0.140 & 0.556 \\
\hline & Glucose & -1.549 & 1.813 & -0.045 & -0.855 & 0.393 & -5.115 & 2.016 \\
\hline
\end{tabular}

Dependent Variable: WSP scores
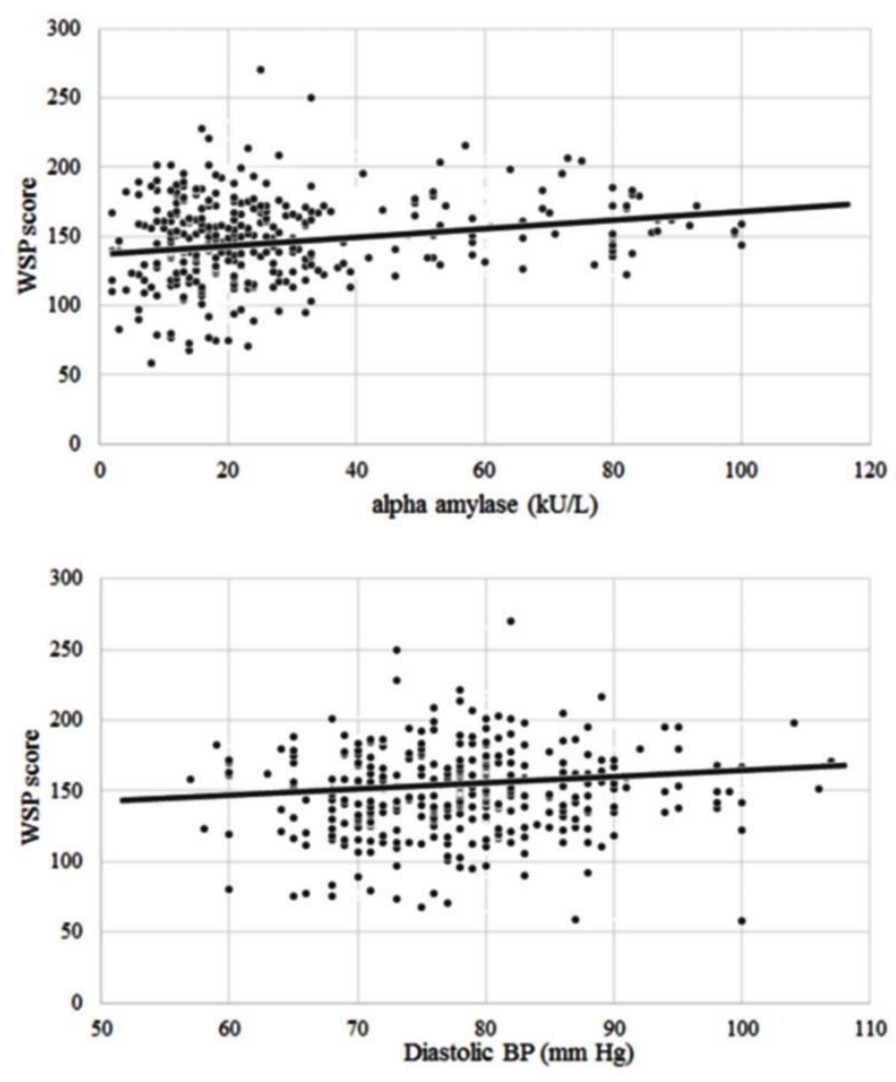

Figure 1: Correlation of collective total scores to salivary alpha-amylase and diastole blood pressure.

\subsection{DISCUSSION}

Salivary biomarkers have received particular attention since they are readily accessible and easily obtained (Nater \& Riohleder, 2009). As a non-invasive method, the salivary alpha-amylase test is the most suitable for detecting the stress without the 'needle' stress.
In addition, by measuring salivary amylase and detecting the stress level, we can potentially develop prevention guidelines for medical professionals at great risk of getting infections. On the other hand, we should remember that to be safe during the COVID-19 period. People need to be calm and boost their immunity. Stress usually strikes down the immune system.

Since the outbreak of COVID-19, the whole clinical setting has been functioning under stress. Consequently, the personnel are experiencing more stress for the visible cause of working in risky places. Several scientists, such as Weiman (1978) and Holmgren and Rice (1999), have made various self-administered questionnaires in order to determine workplace stress in its early stages; by early detection, the person or organization can be prevented or avoided from the numerous unpleasant consequences such as sick leave, physiological and psychological illnesses, and workrelated injuries (Frantz \& Holmgren, 2019). Nonetheless, we chose the Rice (1999) WPS selfesteemed questionnaire because we expected our study participants to be relatively healthy, i.e., they never complain about being sick and leave work (Rice, 1992).

Women, especially nurses, dominate medical professionals' workplaces around the world. Our findings agree that, regardless of whether the work environment, requirements, or workload are the same or different, all people, regardless of gender, experience workplace stress and depend solely on individual characteristics. 
According to the literature, workplace stress is often treated by the gender of the professionals, but the results vary. For some researchers, the work stress is not related to gender (Wong et al., 2013) and others considered that female nurses are more vulnerable to various occupational stresses than men (Lusk., 2007). Furthermore, some authors found that female nurses are more susceptible to psychological stress, whereas men are more susceptible to physiological stressors (Jennings, 2008). For this reason, we considered that gender would play a key role to be stressed during this pandemic period because female nurses feel they have more responsibility for their family (children) besides the work.

Our findings are consistent with a study conducted in 2013 by Finnish researchers, which discovered that young nurses are less exposed to workplace stress than medical professionals with more working experiences (Mauno et al., 2013). We agreed that younger nurses are less exposed to work stress because they work in a fellowship system and are constantly reliant on coworkers for assistance. A study by Takase and colleagues (2016) proposed that nurses over the age of twenty-five who want to keep their jobs are more stressed than middle-aged and elderly workers.

This study is the first attempt to detect work stress among medical professionals by a non-invasive salivary alpha-amylase test. This is the main strength of our work. The limitation of our study is the narrow area of involvement, hence the small sampling size. We covered only three referral main national tertiary centres of Mongolia. We suggested that the human biorhythm could influence the salivary alpha-amylase level. We are planning to investigate the morning and evening salivary alpha-amylase among medical professionals. The study's practical significance is that by detecting the stress among the medical professionals (the nurses), we can provide stress-reducing interventions. In addition, it could provide insights for other researchers to continue this research from different perspectives.

\subsection{CONCLUSIONS}

This study is the first attempt to determine work stress in a non-invasive way. The study results suggest that the COVID-19 pandemic period triggers stress among Mongolian medical professionals. And the salivary alpha-amylase levels could be the supporting test for the WSP. In other words, salivary alpha-amylase is directly indicated in the collective totals score. The biorhythms of the participants can further explain this. In a nutshell, there is a need to monitor the stress level among medical professionals, particularly the nurses in Mongolia, for proper management and intervention programmes, especially during the COVID-19 pandemic.

Acknowledgements: We express our appreciation to colleagues who worked on this research and supported it financially.

Author Contributions: M.J. conceived and designed the research idea, O.D. and N.N. performed the experiments; M.J., and O.D., analyzed the data; A.D. contributed to fund materials/analysis tools; M.J., wrote the paper, A.T., and translated the paper from Mongolian into English.

Conflicts of Interest: The authors declare no conflict of interest.

\section{References}

Ali, N., \& Nater, U. M. (2020). Salivary Alpha-Amylase as a Biomarker of Stress in Behavioral Medicine. International Journal of Behavioral Medicine, 27(3), 337-342. https://doi.org/10.1007/s12529-019-09843-x

Benson, H., Beary, J. F., \& Carol, M. P. (1974). The relaxation response. Psychiatry, 37(1), 37-46. https://doi.org/10.1080/00332747.1974.11023785

Frantz, A., \& Holmgren, K. (2019). The Work Stress Questionnaire (WSQ) - reliability and face validity among male workers. BMC Public Health, 19(1), 1580. https://doi.org/10.1186/s12889-019-7940-5

Jennings, B. M. (2008). Work Stress and Burnout Among Nurses: Role of the Work Environment and Working Conditions. In R. G. Hughes (Ed.), Patient Safety and Quality: An Evidence-Based Handbook for Nurses. Rockville (MD).

Lusk, Edward, Gunkel, Marjaana, Wolff, Birgitta, \& Li, Fang. (2007). Gunkel, M., Lusk, E.J., Wolff, B., \& Li, F. (2007). GenderSpecific Effects at Work: An Empirical Study of Four Countries. Gender, Work and Organization, 14:56-79. Gender, Work and Organization, 14, 56-79. https://doi.org/10.1111/j.1468-0432.2007.00332.x

Marik, P. E., \& Bellomo, R. (2013). Stress hyperglycemia: an essential survival response! Critical Care, 17(2), 305. https://doi.org/10.1186/cc12514

Maslach, C., Schaufeli, W. B., \& Leiter, M. P. (2001). Job burnout. Annual Review of Psychology, 52, 397-422. https://doi.org/10.1146/annurev.psych.52.1.397

Mauno, S., Ruokolainen, M., \& Kinnunen, U. (2013). Does aging make employees more resilient to job stress? Age as a moderator in the job stressor-well-being relationship in three Finnish occupational samples. Aging and Mental Health, 17(4), 411-422. https://doi.org/10.1080/13607863.2012.747077 
Nater, U. M., \& Rohleder, N. (2009). Salivary alpha-amylase as a non-invasive biomarker for the sympathetic nervous system: current state of research. Psychoneuroendocrinology, 34(4), 486-496. https://doi.org/10.1016/j.psyneuen.2009.01.014

Otgonbaatar, Dondonkhuu, Ts, Lkhagvasuren, Ariunaa, Damndinsuren, Tundevrentsen, Aldarmaa, Naranbaatar, Nyam, \& Munkhkhand, Jurmeddorj. (2020). Occupational Stress in Nurse sAA -The Study Provided during the Urged Pandemic COVID-19 Quarantine Period. Psychology, 11, 704-712. https://doi.org/10.4236/psych.2020.115048

Rice, Phillip L. (1992). Stress and health, 2nd ed. Belmont, CA, US: Thomson Brooks/Cole Publishing Co.

Sternberg, E. M. (2006). Neural regulation of innate immunity: a coordinated nonspecific host response to pathogens. Nature Reviews Immunology, 6(4), 318-328. https://doi.org/10.1038/nri1810

Wong, C. A., Cummings, G. G., \& Ducharme, L. (2013). The relationship between nursing leadership and patient outcomes: a systematic review update. Journal of Nursing Management, 21(5), 709-724. https://doi.org/10.1111/jonm.12116 